\title{
Decolorisation of Reactive Red 120 Dye by Using Single-Walled Carbon Nanotubes in Aqueous Solutions
}

\author{
Edris Bazrafshan, ${ }^{1}$ Ferdos Kord Mostafapour, ${ }^{1}$ Ali Reza Hosseini, ${ }^{1}$ \\ Ataolah Raksh Khorshid, ${ }^{1}$ and Amir Hossein Mahvi ${ }^{2,3,4}$ \\ ${ }^{1}$ Health Promotion Research Center, Zahedan University of Medical Sciences, Zahedan, Iran \\ ${ }^{2}$ School of Public Health, Tehran University of Medical Sciences, Tehran, Iran \\ ${ }^{3}$ Center for Solid Waste Research, Institute for Environmental Research, Tehran University of Medical Sciences, Tehran, Iran \\ ${ }^{4}$ National Institute of Health Research, Tehran University of Medical Sciences, Tehran, Iran
}

Correspondence should be addressed to Amir Hossein Mahvi; ahmahvi@yahoo.com

Received 2 June 2012; Revised 14 July 2012; Accepted 15 July 2012

Academic Editor: Mohammad A. Al-Ghouti

Copyright (C) 2013 Edris Bazrafshan et al. This is an open access article distributed under the Creative Commons Attribution License, which permits unrestricted use, distribution, and reproduction in any medium, provided the original work is properly cited.

\begin{abstract}
Dyes are one of the most hazardous chemical compound classes found in industrial effluents and need to be treated since their presence in water bodies reduces light penetration, precluding the photosynthesis of aqueous flora. In the present study, singlewalled carbon nanotubes (SWCNTs) was used as an adsorbent for the successful removal of Reactive Red 120 (RR-120) textile dye from aqueous solutions. The effect of various operating parameters such as initial concentration of dye, contact time, adsorbent dosage and initial $\mathrm{pH}$ was investigated in order to find the optimum adsorption conditions. Equilibrium isotherms were used to identify the possible mechanism of the adsorption process. The optimum $\mathrm{pH}$ for removing of RR-120 dye from aqueous solutions was found to be 5 and for this condition maximum predicted adsorption capacity for RR-120 dye was obtained as $426.49 \mathrm{mg} / \mathrm{g}$. Also, the equilibrium data were also fitted to the Langmuir, Freundlich and BET equilibrium isotherm models. It was found that the data fitted to BET $\left(R^{2}=0.9897\right)$ better than Langmuir $\left(R^{2}=0.9190\right)$ and Freundlich $\left(R^{2}=0.8819\right)$ model. Finally it was concluded that the single-walled carbon nanotubes can be used for dye removal from aqueous solutions.
\end{abstract}

\section{Introduction}

Environmental pollution has recently become a severe problem worldwide [1]. Dyes are one of the most hazardous chemical compound classes found in industrial effluents and need to be treated since their presence in water bodies reduces light penetration, precluding the photosynthesis of aqueous flora $[2,3]$. They are also aesthetically objectionable for drinking and other purposes [4] and can cause allergy, dermatitis, skin irritation [5] and also provoke cancer [6] and mutation in humans [7].

Reactive dyes represent an important portion of the commercial synthetic dyes, mainly because of their excellent binding ability initiated by the formation of a covalent bond between their reactive groups and the surface groups of the textile and cellulose fibers. They are used extensively in textile industries, and their release in the ecosystem represents increasing environmental danger, because of their toxicity, mutagenicity, and nonbiodegradability [8-10]. Also, reactive dyes are, in general, the most problematic among other dyes, as they tend to pass through conventional treatment systems unaffected $[10,11]$. Additionally, reactive dyes are resistant to natural biodegradation, due to the aromatic rings in their structure [12]. Among dyes used in textile industry, Reactive Red-120 (RR-120) is one of the frequently used dyes in textile industries and is a potential threat to the aquatic environment due to its poor biodegradability [1].

Improper treatment and disposal of dye-contaminated wastewaters from textile, dyeing, printing, ink, and related industries have provoked serious environmental concerns all over the world $[13,14]$. Removal of dye in wastewater has been made by physical, physicochemical, biological, and/or chemical processes [15-17]. The conventional treatment process of textile effluents involves numerous stages due to the 
TABLE 1: Some characteristics of the investigated dye.

\begin{tabular}{ll}
\hline Characteristic & Reactive Red-120 (RR-120) \\
\hline Molecular formula & $\mathrm{C}_{44} \mathrm{H}_{24} \mathrm{C}_{12} \mathrm{~N}_{14} \mathrm{Na}_{6} \mathrm{O}_{20} \mathrm{~S}_{6}$ \\
Color index name & Reactive Red-120 \\
Molecular weight & $1469,34 \mathrm{~g} / \mathrm{mol}$ \\
Water solubility & $70\left(\mathrm{~g} \mathrm{~L}^{-1}\right)$ \\
$\lambda_{\max }$ & 515 \\
Class & Diazo (-N=N- bond) \\
\hline
\end{tabular}

characteristics of the production process [18]. Conventional treatment involves a process of coagulation/flocculation. This is a versatile process, which can be used alone or combined with biological treatments, as a way of removing suspended solids and organic material, as well as promoting the extensive removal of dyes from textile industry effluents $[19,20]$. However, this approach presents the disadvantage of generating a large volume of sludge. This sludge is rich in dyes, as well as other substances used in the textile process. This is a problem, as the waste must be discarded properly to avoid environmental contamination [18]. Also, biological treatment and enzymatic treatment [21-23], ozone treatment $[24,25]$, chemical oxidation, photocatalytic processes [14, 26], sonochemical processes [27], nanoparticles [28], and membrane processes [29] were used for removal of dye from textile effluents. However, some of these methods are limited due to their high operational costs and problems.

The most efficient procedure for removal of synthetic dyes from industrial effluents is the adsorption procedure, because the dye species are transferred from the water effluent to a solid phase, diminishing the effluent volume to a minimum. Subsequently, the adsorbent can be regenerated or kept in a dry place without direct contact with the environment [3]. Also, adsorption has proven to be a reliable treatment methodology due to its low capital investment cost, simplicity of design, ease of operation, and insensitivity to toxic substances, but its application is limited by the high price of some adsorbents and the large amounts of wastewater normally involved. Activated carbon [30, 31], mesoporous carbon [8], clay minerals [32], hydrotalcite [11], biopolymers such as chitosan beads [33] and quaternary chitosan [9], and agricultural by-products [34, 35] are a few of the adsorptive materials that have been tested for the treatment of wastewaters.

Carbon nanotubes (CNTs), ever since their discovery, have attracted extensive attention due to their unique physicochemical and electrical properties. CNTs include singlewalled carbon nanotubes (SWCNTs) and multiwalled carbon nanotubes (MWCNTs) depending on the number of layers comprising those [36]. CNTs, which are considered to be extremely superior adsorbents due to their high specific surface area and large micropore volume, have been utilized for the sorption of a number of different organic compounds and inorganic ions [37-45], since the first report of their successful removal of dioxin [46]. For the first time Long and Yang reported that CNTs could be used as superior adsorbents for dioxin and the removal capacity of CNTs was found to be higher than that of activated carbon [46].

In the present study, single-walled carbon nanotubes (SWCNTs) were chosen as sorbent for removal of RR-120 dye. The aim of this study is to investigate the adsorption of RR-120 dye on single-walled carbon nanotubes (SWCNTs) under various conditions. So, the influence of several operating parameters such as initial concentration, contact time, adsorbent dosage, and initial $\mathrm{pH}$ of solution was investigated. Equilibrium isotherms were used to identify the possible mechanism of the adsorption process. This information will be useful for designing and operating color removal systems based on different local water qualities.

\section{Experimental}

2.1. Chemicals and Reagents. The model textile reactive dye (Reactive Red 120) was purchased from Merck Company (Germany). The chemical structure and some properties of the Reactive Red-120 dye are presented in Table 1 and Figure 1. Also, all other chemicals and reagents used were analytical grade (Merck Company, Germany). Stock solution of RR-120 dye $(1000 \mathrm{mg} / \mathrm{L})$ was prepared by dissolving the dye in $1 \mathrm{~L}$ double distilled water. For treatment experiments, the dye solutions with concentrations in the range of $10-200 \mathrm{mg} / \mathrm{L}$ were prepared by successive dilution of the stock solution with double distilled water.

2.2. Adsorbent Preparation. SWCNTs (provided from Research Institute of Petroleum Industry (RIPI), Tehran, Iran) were selected as adsorbents to study the adsorption characteristics of RR-120 dye from aqueous solutions. On the basis of the information provided by the manufacturer, the SWCNTs were synthesized by catalytic chemical vapor deposition (CVD) method. The morphologies of SWCNTs were examined by using SEM (JEOL microscope, model JSM-6700F) (see Figure 2). The size of the outer diameter for the SWCNTs was $1-2 \mathrm{~nm}$. The length of SWCNTs was $10 \mu \mathrm{m}$. Furthermore, specific surface area of SWCNTs was more than $700 \mathrm{~m}^{2} / \mathrm{g}$, and the mass ratio of the amorphous carbon of SWCNTs was less than 5\%.

Because carbon nanotubes had the amorphous carbon and therefore the adsorption rate is very low, therefore, carbon nanotube should be purified. In order to functionalize SWCNTs, $0.3 \mathrm{~g}$ of the SWCNTs was dispersed in $25 \mathrm{~mL}$ of nitric acid (65 wt \%) in a $100 \mathrm{~mL}$ round bottom flask equipped with a condenser and the dispersion was refluxed under magnetic stirring for $48 \mathrm{~h}$. After that, the resulting dispersion was diluted in water and filtered. The resulting solid was washed up to neutral $\mathrm{pH}$, and the sample was dried in vacuum at $40^{\circ} \mathrm{C}$ overnight.

2.3. Dye Removal Experiments. Dye removal experiments with the synthesized SWCNTs were carried out as batch tests in $250 \mathrm{~mL}$ flasks under magnetic stirring. The experiments were conducted individually for each of the model dyes, but the same procedure was used for both, as detailed below. Each test consisted of preparing a $100 \mathrm{~mL}$ of dye solution with a 
TABLE 2: Isotherm parameters for adsorption of RR-120 onto SWCNTs at $23 \pm 2^{\circ} \mathrm{C}$.

\begin{tabular}{lcccccccc}
\hline & Langmuir isotherm & \multicolumn{3}{c}{ Freundlich isotherm } & \multicolumn{3}{c}{ BET isotherm } \\
$q_{m}(\mathrm{mg} / \mathrm{g})$ & $k_{L}(\mathrm{~L} / \mathrm{mg})$ & $R^{2}$ & $k_{f}$ & $n$ & $R^{2}$ & $A$ & $X_{m}(\mathrm{mg} / \mathrm{g})$ & $R^{2}$ \\
\hline 2500 & 0.031 & 0.9190 & 134.8 & 1.07 & 0.8819 & 384.6 & 0.00025 & 0.9897 \\
\hline
\end{tabular}<smiles>[2H]N(c1ccc(N([2H])c2nc(Cl)nc(Nc3cc(OC)cc4cc(S(C)(=O)=O)c(N=Nc5ccccc5S(C)(=O)=O)c(O)c34)n2)cc1)c1nc(Cl)nc(Nc2cc([N+](=O)[O-])cc3cc(O[N+](=O)[O-])c(N=Nc4ccccc4S(C)(=O)=O)c(O)c23)n1</smiles>

FIGURE 1: The chemical structure of the Reactive Red-120.

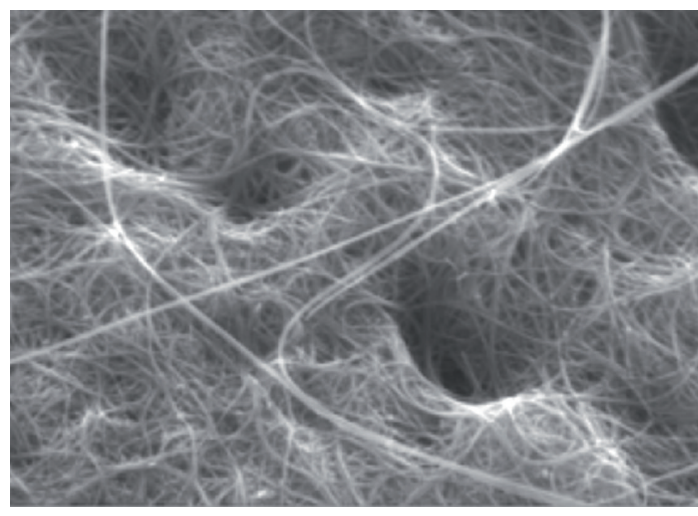

FIGURE 2: SEM image of SWCNTs sample.

desired initial concentration and $\mathrm{pH}$ by diluting the stock dye solutions with double distilled water, and transferring it into the beaker on the magnetic stirrer. The $\mathrm{pH}$ of the solution was adjusted using $0.1 \mathrm{NHCl}$ or $\mathrm{NaOH}$ solutions by a $\mathrm{pH}$ meter model E520 (Metrohm Herisau, Switzerland). A known mass of SWCNTs powder (adsorbent dosage) was then added to the solution, and the obtained suspension was immediately stirred for a predefined time. After the mixing time elapsed, the suspension was allowed to settle and the supernatant was analyzed using a double beam UV/vis spectrophotometer (Shimadzu, Tokyo, Japan; Model 1601) at $515 \mathrm{~nm}$ for Reactive
Red-120. Then the amount of dye (RR-120 dye) adsorbed, $q_{e}$ (mg/g), was obtained as follows:

$$
q_{e}=\frac{\left(C_{0}-C_{e}\right) V}{M}
$$

where $C_{0}$ and $C_{e}$ are the initial and equilibrium liquid phase concentration of dye $(\mathrm{mg} / \mathrm{L})$, respectively. $V$ is the volume of the solution ( $\mathrm{L}$ ) and $M$ is the amount of adsorbent used ( $\mathrm{g}$ ).

To express the percent of dye removal, the following equation was used:

$$
\%=\frac{\left(C_{0}-C_{f}\right)}{C_{0}} \times 100,
$$

where $C_{0}$ and $C_{f}$ represent the initial and final (after adsorption) dye concentrations, respectively. All tests were performed in duplicate to insure the reproducibility of the results; the mean of the two measurements is reported. Furthermore, all experiments were performed at room temperature $\left(23 \pm 2^{\circ} \mathrm{C}\right)$. The investigated ranges of the experimental variables were as follows: dye concentration $(10,50,100,150$, $200 \mathrm{mg} / \mathrm{L}$ ), initial $\mathrm{pH}$ of solution (3-12), SWCNTs dosage $(0.01-0.05 \mathrm{~g} / \mathrm{L})$, and mixing time $(30,60,90,120,150,180$, $210,240 \mathrm{~min})$.

\section{Results and Discussion}

3.1. Effect of Initial $p H$. It is known that the solution $\mathrm{pH}$ can affect the surface charge of the adsorbent, the degree 


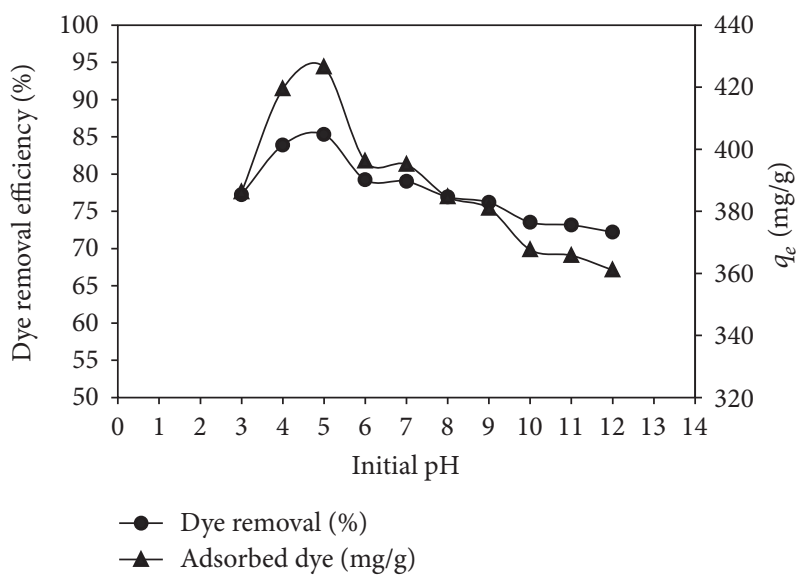

Figure 3: Effect of initial $\mathrm{pH}$ on the adsorption of RR-120 to SWCNTs. $\left(C_{0}=50 \mathrm{mg} / \mathrm{L}\right.$, contact time $=180 \mathrm{~min}$, adsorbent dosage $=0.01 \mathrm{~g} / \mathrm{L}$, temperature $=23 \pm 2^{\circ} \mathrm{C}$ ).

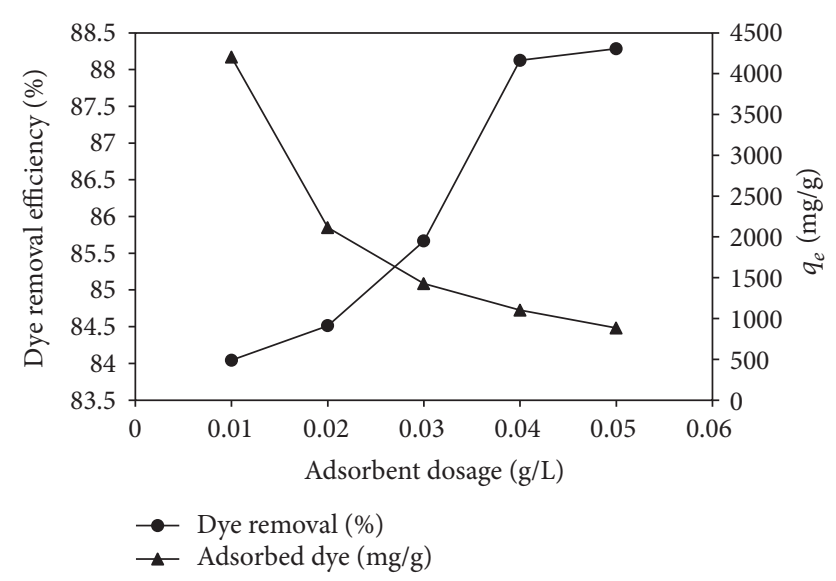

FIGURE 4: Effect of adsorbent dosage on RR-120 adsorption onto SWCNTs. $\left(C_{0}=50 \mathrm{mg} / \mathrm{L}\right.$, contact time $=180 \mathrm{~min}, \mathrm{pH}=5$, temperature $\left.=23 \pm 2^{\circ} \mathrm{C}\right)$.

of ionization of the different pollutants, the dissociation of functional groups on the active sites of the adsorbent as well as the structure of the dye molecule [38]. The solution $\mathrm{pH}$ would affect both aqueous chemistry and surface binding sites of the adsorbent. So the solution $\mathrm{pH}$ is an important parameter during the dye adsorption process.

At present study, the effect of $\mathrm{pH}$ on the RR-120 dye adsorption capacities of the SWCNTs was conducted at varying $\mathrm{pH}(\mathrm{pH} \mathrm{3-12)}$ with $50 \mathrm{mg} / \mathrm{L}$ fixed initial dye concentrations and adsorbent dosage $0.01 \mathrm{~g} / \mathrm{L}$ for $180 \mathrm{~min}$. As can be seen from Figure 3, the adsorption of RR-120 dye onto SWCNTs is intimately dependent on initial $\mathrm{pH}$ of solution. The adsorption capacity of RR-120 dye increases with increasing solution $\mathrm{pH}$ from 3 to 5 and decreases slightly when solution $\mathrm{pH}$ is above 5 . Therefore, in order to continue the adsorption studies, the initial $\mathrm{pH}$ was fixed at 5. The maximum adsorption capacity of the SWCNTs was $426.49 \mathrm{mg} / \mathrm{g}$ at $\mathrm{pH} 5$, initial dye concentration of $50 \mathrm{mg} / \mathrm{L}$ and $23 \pm 2^{\circ} \mathrm{C}$, when $85.3 \%$ of the dye was removed. Similar results were reported by other researchers [47-50].

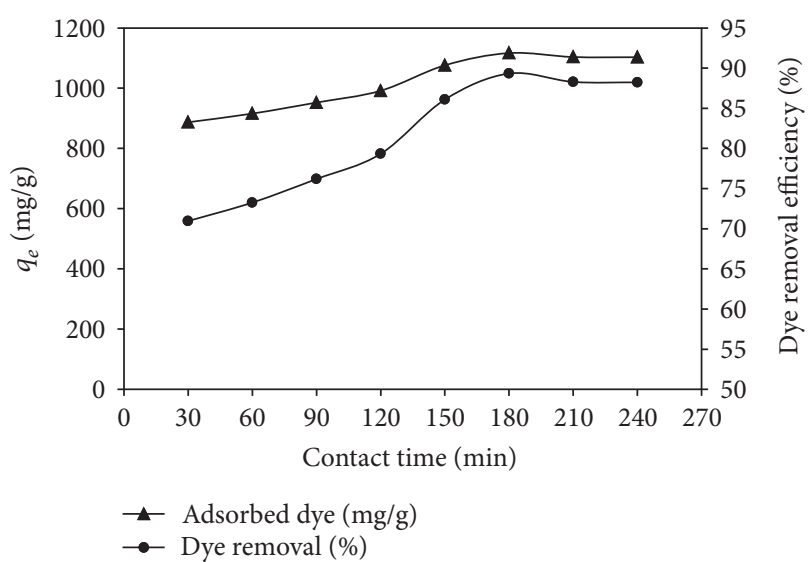

FIGURE 5: Effect of contact time on RR-120 adsorption onto SWCNTs. $\left(C_{0}=50 \mathrm{mg} / \mathrm{L}\right.$, adsorbent dosage $=0.04 \mathrm{~g} / \mathrm{L}, \mathrm{pH}=5$, temperature $=23 \pm 2^{\circ} \mathrm{C}$ ).

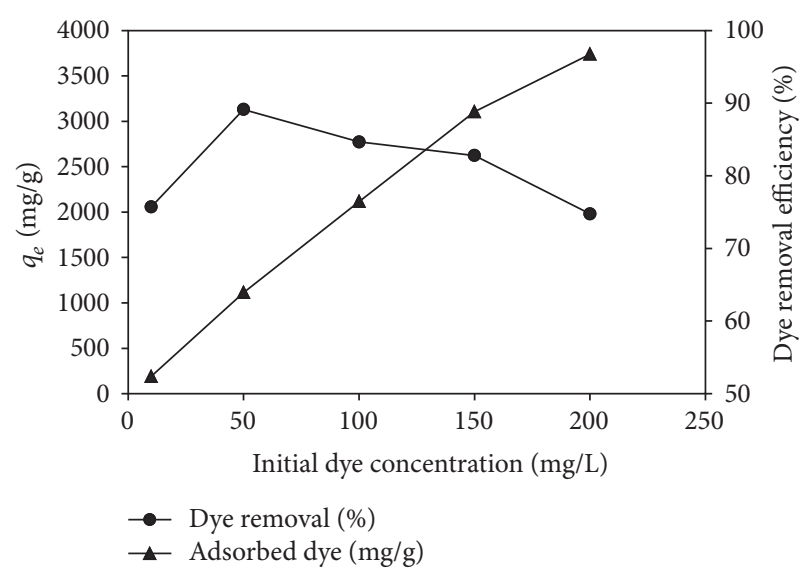

FIGURE 6: Effect of initial dye concentrations on RR-120 adsorption onto SWCNTs. (Adsorbent dosage $=0.04 \mathrm{~g} / \mathrm{L}$, contact time $=$ $180 \mathrm{~min}, \mathrm{pH}=5$, temperature $=23 \pm 2^{\circ} \mathrm{C}$ ).

It is well known that the surface of CNTs contains some oxygen groups such as carboxylic groups $(-\mathrm{COOH})$ and hydroxyl groups $(-\mathrm{OH})$ after acid treatment [51]. At lower $\mathrm{pH}$ values, due to the protonation of electron $\pi$ rich regions on the surface of SWCNTs, the positive surface charge can be formed. Under these conditions, the uptake of negative charged dyes (RR-120) will be high. When $\mathrm{pH}$ increases, the carboxylic groups are ionized and the negative charge density on the surface increases, resulting in reduced removal of dyes.

3.2. Effect of SWCNTs Dosage. The adsorbent concentration is an important parameter because this determines the capacity of the adsorbent (SWCNTs) for a given initial RR120 dye concentration. In order to attain the optimal amount of SWCNTs for the adsorption of RR-120 dye, $0.01-0.05 \mathrm{~g} / \mathrm{L}$ adsorbent (SWCNTs) was used for adsorption experiments at fixed initial $\mathrm{pH}(\mathrm{pH} 5)$, initial dye concentration $(50 \mathrm{mg} / \mathrm{L})$, and temperature $\left(23 \pm 2^{\circ} \mathrm{C}\right)$ for $180 \mathrm{~min}$. 


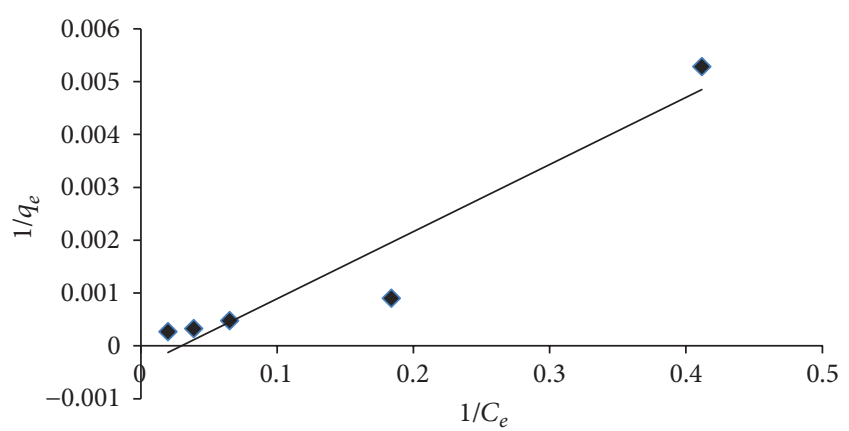

FIGURE 7: Langmuir isotherm for sorption of RR-120 onto SWCNTs $\left(R^{2}=0.9190\right)$.

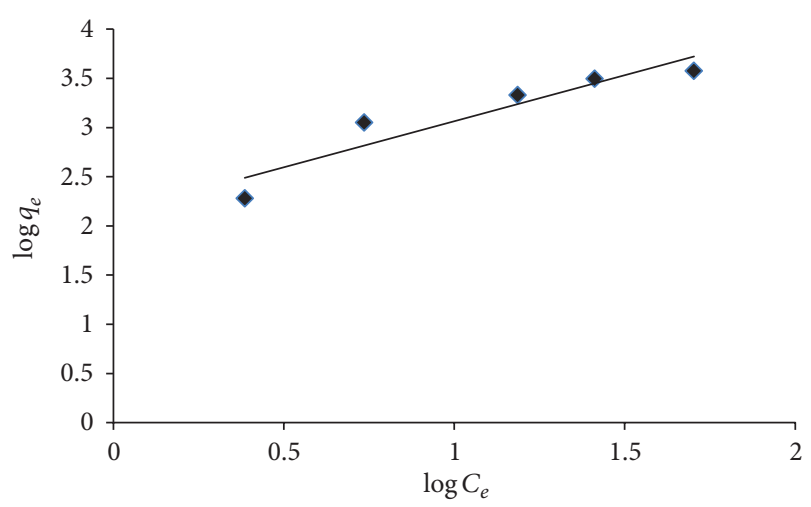

FIGURE 8: Freundlich isotherm for sorption of RR-120 onto SWCNTs $\left(R^{2}=0.8819\right)$.

As it can be seen from Figure 4, it was found that the adsorption percentage increased with the increasing amount of SWCNTs, and when the amount exceeded $0.05 \mathrm{~g}$, the adsorption percentage reached $88.28 \%$ (adsorption capacity $882.83 \mathrm{mg} / \mathrm{g}$ ). An increase in adsorption rate with adsorbent dosage can be attributed to increased surface area and the availability of more adsorption sites [52]. Similar results were reported by other researchers $[47,53]$. Nevertheless, as the removal efficiency of dye at adsorbent dosage 0.04 and $0.05 \mathrm{~g} / \mathrm{L}$ was not significant, thus, for equilibrium studies the mean dosage $(0.04 \mathrm{~g} / \mathrm{L})$ of SWCNTs was selected as the optimum dose.

3.3. Effect of Contact Time. Contact time is one of the most important parameters for practical application. Figure 5 shows the effect of contact time on the adsorption capacity and percent removal of RR-120 dye onto the SWCNTs at $\mathrm{pH}$ 5 and $0.04 \mathrm{~g} / \mathrm{L}$ adsorbent dosage for initial dye concentration $50 \mathrm{mg} / \mathrm{L}$. The adsorption capacity and percent removal of RR-120 dye onto the SWCNTs drastically increase during the initial adsorption stage and then continue to increase at a relatively slow speed with contact time until a state of equilibrium is attained after $180 \mathrm{~min}$. The maximum adsorption efficiency of RR-120 dye onto SWCNTs was found to be $89.33 \%(1116.62 \mathrm{mg} / \mathrm{g})$ at contact time of $180 \mathrm{~min}$.

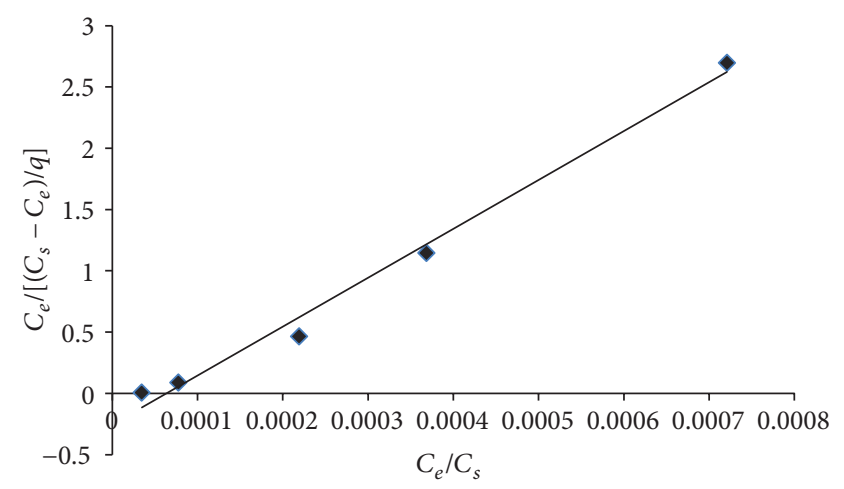

FIGURE 9: BET isotherm for sorption of RR-120 onto SWCNTs $\left(R^{2}\right.$ $=0.9897)$.

Hence, in the present study, $180 \mathrm{~min}$ was chosen as the equilibrium time. Generally the removal rate of sorbate is rapid initially, but it gradually decreases with time until it reaches equilibrium. This phenomenon is attributed to the fact that a large number of vacant surface sites are available for adsorption at the initial stage, and after a lapse of time, the remaining vacant surface sites are difficult to be occupied due to repulsive forces between the solute molecules on the solid and bulk phases. Similar findings were reported by other researchers $[47,54]$.

3.4. Effect of Initial Dye Concentration. The initial concentration provides an important driving force to overcome all mass transfer resistance of the dye between the aqueous and solid phases [55]. At present study, the effects of initial dye concentration on adsorption were studied at $23 \pm 2^{\circ} \mathrm{C}$ and $0.04 \mathrm{~g} / \mathrm{L}$ adsorbent concentration for $180 \mathrm{~min}$.

Remarkably, the adsorption capacity of RR-120 dye increases (Figure 6), but the percent removal of RR-120 dye decreases with the increase in initial concentration, suggesting that the adsorption of RR-120 dye onto SWCNTs is highly dependent on initial dye concentration. As can be seen from Figure 6, when the initial RR-120 dye concentration increases from 10 to $200 \mathrm{mg} / \mathrm{L}$, the equilibrium sorption capacities of SWCNTs increase from 189.27 to $3738.4 \mathrm{mg} / \mathrm{g}$. The maximum adsorption efficiency of RR-120 dye onto SWCNTs was found to be $89.12 \%(1114.0 \mathrm{mg} / \mathrm{g})$ at contact time of $180 \mathrm{~min}$. These results is in accordance with obtained findings by other researchers $[47,54,55]$.

The initial dye concentrations provide an important driving force to overcome the mass transfer resistance of the dye between the aqueous phases and the solid phases, so increasing initial concentrations would enhance the adsorption capacity of dye. On the other hand, the dye adsorption process generally involves the first transport of dye molecules from bulk solution through liquid film to the exterior surface of adsorbent and then from the exterior surface to the pores of the adsorbent, which reflects that the adsorption of dye onto the adsorbent is relevant to the initial concentration. In general, the total number of available adsorption sites is fixed for a given adsorbent dose. It is reasonable to particulate 
that the larger ratio of active adsorption sites of the adsorbent is available at lower initial concentration. Therefore, the percentage removal of dye is greater at lower initial concentration but smaller at higher initial concentration.

3.5. Adsorption Isotherms. Isotherms study can describe how an adsorbate interacts with adsorbent. The isotherm provides a relationship between the concentration of dye in solution and the amount of dye adsorbed on the solid phase when both phases are in equilibrium. At present study equilibrium adsorption data were analyzed by using the Langmuir, Freundlich and BET isotherm models (Figures 7, 8, and 9). Also, analysis of isotherms was used to describe the experimental adsorption data, and then best results can be obtained when correlation coefficients $\left(R^{2}\right)$ come close to 1 . High values of $R^{2}$ (close or equal to 1 ) indicate the conformity among experimental data with model isotherm [47].

The adsorption isotherm models of Langmuir, Freundlich, and BET can be represented in the linear form as follows:

$$
\begin{gathered}
\frac{1}{q_{e}}=\frac{1}{q_{m}}+\frac{1}{q_{m} K_{l}} \frac{1}{C_{e}}, \\
\log q_{e}=\log K_{f}+\frac{1}{n} \log C_{e}, \\
\frac{C_{e}}{\left(C_{i}-C_{e}\right) q_{e}}=\frac{1}{A X_{m}}+\frac{A-1}{A X_{m}},
\end{gathered}
$$

where $q_{e}$ is the amount of dye adsorbed per specific amount of adsorbent ( $\mathrm{mg} / \mathrm{g}), C_{e}$ is equilibrium concentration of RR-120 dye (mg/L), $K_{L}$ is Langmuir constant, and $q_{m}$ is the maximum amount of RR-120 dye required to form a monolayer $(\mathrm{mg} / \mathrm{g})$. $K_{f}$ and $1 / n$ are the Freundlich constants related to adsorption capacity and adsorption intensity, respectively. $C_{i}$ is the initial concentration of dye in solution $(\mathrm{mg} / \mathrm{L}), \mathrm{A}$ is a constant to describe the energy of interaction between the solute and the adsorbent surface, and $X_{m}$ is the amount of solute adsorbed in forming a complete monolayer $(\mathrm{mg} / \mathrm{g})$.

The $R^{2}$ values of Langmuir, Freundlich, and BET models (Table 2) are $0.9190,0.8819$, and 0.9897 , respectively, indicating that the BET model is more suitable for describing the adsorption equilibrium of Reactive Red-120 dye onto SWCNTs. In the Langmuir model, it is assumed that the site energy for adsorption is the same for all surface sites and does not depend on degree of coverage and that the largest capacity corresponds to only one monolayer. These assumptions are not valid for most adsorbents because, for example, activated carbon has a wide range of pore size that continues to adsorb organics as the concentration increases. While the BET isotherm does allow for multiple layers, it is assumed in the BET equation that site energy is the same for the first layer and equal to the free energy of precipitation for subsequent layers. In reality, the site energy of adsorption varies widely for most adsorbents because adsorbents, such as activated carbon, are very heterogeneous and the site energy varies considerably with surface coverage. The Freundlich equation is used to describe isotherm data for heterogeneous adsorbents (varying site energies) much better than the Langmuir or BET equations [56].

\section{Conclusions}

From the present study, it could be concluded that the SWCNTs can be used effectively for the removal of the RR120 dye from aqueous solutions. The percentage eliminated was found to depend on the amount of adsorbent, $\mathrm{pH}$, the initial concentration of the dye, and the dye-adsorbent contact time. The SWCNTs were able to remove up to $89 \%$ of RR-120 dye from solutions whose initial concentration varied between 10 and $200 \mathrm{mg} / \mathrm{L}$. The adsorption of RR-120 dye on SWCNTs has been described by the Langmuir, Freundlich, and BET isotherm models. Also the results of this study showed that the BET model is more suitable for describing the adsorption equilibrium of Reactive Red-120 dye onto SWCNTs.

\section{Acknowledgments}

This study was funded by the health research deputy of Zahedan University of Medical Sciences (Project no. 902377) and was conducted in the Chemical Laboratory of School of Public Health, Zahedan University of Medical Sciences. It is also worth to say that there is no direct relation or financial support by any commercial companies mentioned in the paper with this research.

\section{References}

[1] J. Paul, K. P. Rawat, K. S. S. Sarma, and S. Sabharwal, "Decoloration and degradation of Reactive Red-120 dye by electron beam irradiation in aqueous solution," Applied Radiation and Isotopes, vol. 69, no. 7, pp. 982-987, 2011.

[2] B. Royer, N. F. Cardoso, E. C. Lima et al., "Applications of Brazilian pine-fruit shell in natural and carbonized forms as adsorbents to removal of methylene blue from aqueous solutions-Kinetic and equilibrium study," Journal of Hazardous Materials, vol. 164, no. 2-3, pp. 1213-1222, 2009.

[3] E. C. Lima, B. Royer, J. C. P. Vaghetti et al., "Application of Brazilian pine-fruit shell as a biosorbent to removal of reactive red 194 textile dye from aqueous solution. Kinetics and equilibrium study," Journal of Hazardous Materials, vol. 155, no. 3, pp. 536-550, 2008.

[4] B. Royer, N. F. Cardoso, E. C. Lima, T. R. Macedo, and C. Airoldi, "A useful organofunctionalized layered silicate for textile dye removal," Journal of Hazardous Materials, vol. 181, no. 1-3, pp. 366-374, 2010.

[5] D. S. Brookstein, "Factors associated with textile pattern dermatitis caused by contact allergy to dyes, finishes, foams, and preservatives," Dermatologic Clinics, vol. 27, no. 3, pp. 309-322, 2009.

[6] R. O. Alves de Lima, A. P. Bazo, D. M. F. Salvadori, C. M. Rech, D. P. Oliveira, and G. A. Umbuzeiro, "Mutagenic and carcinogenic potential of a textile azo dye processing plant effluent that impacts a drinking water source," Mutation Research, vol. 626, no. 1-2, pp. 53-60, 2007.

[7] P. A. Carneiro, G. A. Umbuzeiro, D. P. Oliveira, and M. V. B. Zanoni, "Assessment of water contamination caused by a 
mutagenic textile effluent/dyehouse effluent bearing disperse dyes," Journal of Hazardous Materials, vol. 174, no. 1-3, pp. 694-699, 2010.

[8] D. D. Asouhidou, K. S. Triantafyllidis, N. K. Lazaridis, K. A. Matis, S. S. Kim, and T. J. Pinnavaia, "Sorption of reactive dyes from aqueous solutions by ordered hexagonal and disordered mesoporous carbons," Microporous and Mesoporous Materials, vol. 117, no. 1-2, pp. 257-267, 2009.

[9] S. Rosa, M. C. M. Laranjeira, H. G. Riela, and V. T. Fávere, "Cross-linked quaternary chitosan as an adsorbent for the removal of the reactive dye from aqueous solutions," Journal of Hazardous Materials, vol. 155, no. 1-2, pp. 253-260, 2008.

[10] C. I. Pearce, J. R. Lloyd, and J. T. Guthrie, "The removal of colour from textile wastewater using whole bacterial cells: a review," Dyes and Pigments, vol. 58, no. 3, pp. 179-196, 2003.

[11] N. K. Lazaridis, T. D. Karapantsios, and D. Georgantas, "Kinetic analysis for the removal of a reactive dye from aqueous solution onto hydrotalcite by adsorption," Water Research, vol. 37, no. 12, pp. 3023-3033, 2003.

[12] P. Karacakaya, N. K. Kiliç, E. Duygu, and G. Dönmez, "Stimulation of reactive dye removal by cyanobacteria in media containing triacontanol hormone," Journal of Hazardous Materials, vol. 172, no. 2-3, pp. 1635-1639, 2009.

[13] S. Netpradit, P. Thiravetyan, and S. Towprayoon, "Application of 'waste' metal hydroxide sludge for adsorption of azo reactive dyes," Water Research, vol. 37, no. 4, pp. 763-772, 2003.

[14] H. L. Liu and Y. R. Chiou, "Optimal decolorization efficiency of reactive red 239 by UV/ZnO photocatalytic process," Journal of the Chinese Institute of Chemical Engineers, vol. 37, pp. 289-298, 2006.

[15] K. Vijayaraghavan and Y. S. Yun, "Biosorption of C.I. Reactive Black 5 from aqueous solution using acid-treated biomass of brown seaweed Laminaria sp.," Dyes and Pigments, vol. 76, no. 3, pp. 726-732, 2008.

[16] Z. Aksu and G. Karabayir, "Comparison of biosorption properties of different kinds of fungi for the removal of Gryfalan Black RL metal-complex dye," Bioresource Technology, vol. 99, no. 16, pp. 7730-7741, 2008.

[17] C. Namasivayam and D. Kavitha, "Removal of Congo Red from water by adsorption onto activated carbon prepared from coir pith, an agricultural solid waste," Dyes and Pigments, vol. 54, no. 1, pp. 47-58, 2002.

[18] P. C. Vandevivere, R. Bianchi, and W. Verstraete, “Treatment and reuse of wastewater from the textile wet-processing industry: review of emerging technologies," Journal of Chemical Technology and Biotechnology, vol. 72, no. 4, pp. 289-302, 1998.

[19] O. Tunay, I. Kabdasli, G. Eremektar, and D. Orhon, "Color removal from textile wastewaters," Water Science and Technology, vol. 34, pp. 9-16, 1996.

[20] Y. Anjaneyulu, N. S. Chary, and D. S. S. D. Raj, “Decolourization of industrial effluents available methods and emerging technologies-a review," Reviews in Environmental Science and Biotechnology, vol. 4, pp. 245-273, 2005.

[21] F. Gholami-Borujeni, A. H. Mahvi, S. Naseri, M. A. Faramarzi, R. Nabizadeh, and M. Alimohammadi, "Application of immobilized horseradish peroxidase for removal and detoxification of azo dye from aqueous solution," Research Journal of Chemistry and Environment, vol. 15, no. 2, pp. 217-222, 2011.

[22] F. Gholami-Borujeni, A. H. Mahvi, S. Nasseri, M. A. Faramarzi, R. Nabizadeh, and M. Alimohammadi, "Enzymatic treatment and detoxification of acid orange 7 from textile wastewater,"
Applied Biochemistry and Biotechnology, vol. 165, no. 5-6, pp. 1274-1284, 2011.

[23] M. H. Dehghani, A. R. Mesdaghinia, S. Nasseri, A. H. Mahvi, and K. Azam, "Application of SCR technology for degradation of reactive yellow dye in aqueous solution," Water Quality Research Journal of Canada, vol. 43, no. 2-3, pp. 183-187, 2008.

[24] A. Gutowska, J. K. Czaplińska, and W. K. Jóźwiak, “Degradation mechanism of Reactive Orange 113 dye by $\mathrm{H}_{2} \mathrm{O}_{2} / \mathrm{Fe}^{2+}$ and ozone in aqueous solution," Dyes and Pigments, vol. 74, no. 1, pp. 41-46, 2006.

[25] E. Kusvuran, O. Gulnaz, A. Samil, and O. Yildirim, "Decolorization of malachite green, decolorization kinetics and stoichiometry of ozone-malachite green and removal of antibacterial activity with ozonation processes," Journal of Hazardous Materials, vol. 186, no. 1, pp. 133-143, 2011.

[26] T. Clark, M. Bruce, and S. Anderson, "Decolorisation of extraction stage bleach plant effluent by combined hypochlorite oxidation and anaerobic treatment," Water Science and Technology, vol. 29, no. 5-6, pp. 421-432, 1994.

[27] A. Maleki, A. H. Mahvi, R. Ebrahimi, and Y. Zandsalimi, "Study of photochemical and sonochemical processes efficiency for degradation of dyes in aqueous solution," Korean Journal of Chemical Engineering, vol. 27, no. 6, pp. 1805-1810, 2010.

[28] A. H. Mahvi, M. Ghanbarian, S. Nasseri, and A. Khairi, "Mineralization and discoloration of textile wastewater by $\mathrm{TiO}_{2}$ nanoparticles," Desalination, vol. 238, no. 1-3, pp. 309-316, 2009.

[29] S. Yu, M. Liu, M. Ma, M. Qi, Z. Lü, and C. Gao, "Impacts of membrane properties on reactive dye removal from dye/salt mixtures by asymmetric cellulose acetate and composite polyamide nanofiltration membranes," Journal of Membrane Science, vol. 350, no. 1-2, pp. 83-91, 2010.

[30] P. K. Malik, "Dye removal from wastewater using activated carbon developed from sawdust: adsorption equilibrium and kinetics," Journal of Hazardous Materials, vol. 113, no. 1-3, pp. 81-88, 2004.

[31] E. Demirbas, M. Kobya, and M. T. Sulak, "Adsorption kinetics of a basic dye from aqueous solutions onto apricot stone activated carbon," Bioresource Technology, vol. 99, no. 13, pp. 5368-5373, 2008.

[32] S. D. Lambert, N. J. D. Graham, C. J. Sollars, and G. D. Fowler, "Evaluation of inorganic adsorbents for the removal of problematic textile dyes and pesticides," Water Science and Technology, vol. 36, no. 2-3, pp. 173-180, 1997.

[33] M.-S. Chiou and H.-Y. Li, "Equilibrium and kinetic modeling of adsorption of reactive dye on cross-linked chitosan beads," Journal of Hazardous Materials, vol. 93, no. 2, pp. 233-248, 2002.

[34] X. S. Wang, Y. Zhou, Y. Jiang, and C. Sun, "The removal of basic dyes from aqueous solutions using agricultural by-products," Journal of Hazardous Materials, vol. 157, pp. 374-385, 2008.

[35] F. Çiçek, D. Özer, A. Özer, and A. Özer, "Low cost removal of reactive dyes using wheat bran," Journal of Hazardous Materials, vol. 146, no. 1-2, pp. 408-416, 2007.

[36] J. Hu, C. Chen, X. Zhu, and X. Wang, "Removal of chromium from aqueous solution by using oxidized multiwalled carbon nanotubes," Journal of Hazardous Materials, vol. 162, no. 2-3, pp. 1542-1550, 2009.

[37] L. Zhang, T. Xu, X. Liu, Y. Zhang, and H. Jin, "Adsorption behavior of multi-walled carbon nanotubes for the removal of olaquindox from aqueous solutions," Journal of Hazardous Materials, vol. 197, pp. 389-396, 2011. 
[38] L. Ai, C. Zhang, F. Liao et al., "Removal of methylene blue from aqueous solution with magnetite loaded multi-wall carbon nanotube: kinetic, isotherm and mechanism analysis," Journal of Hazardous Materials, vol. 198, pp. 282-290, 2011.

[39] C.-H. Wu, "Adsorption of reactive dye onto carbon nanotubes: equilibrium, kinetics and thermodynamics," Journal of Hazardous Materials, vol. 144, no. 1-2, pp. 93-100, 2007.

[40] C. Lu, Y.-L. Chung, and K.-F. Chang, "Adsorption of trihalomethanes from water with carbon nanotubes," Water Research, vol. 39, no. 6, pp. 1183-1189, 2005.

[41] C. J. M. Chin, L. C. Shih, H. J. Tsai, and T. K. Liu, "Adsorption of o-xylene and p-xylene from water by SWCNTs," Carbon, vol. 45, no. 6, pp. 1254-1260, 2007.

[42] A. Duran, M. Tuzen, and M. Soylak, "Preconcentration of some trace elements via using multiwalled carbon nanotubes as solid phase extraction adsorbent," Journal of Hazardous Materials, vol. 169, no. 1-3, pp. 466-471, 2009.

[43] M. Tuzen, K. O. Saygi, C. Usta, and M. Soylak, "Pseudomonas aeruginosa immobilized multiwalled carbon nanotubes as biosorbent for heavy metal ions," Bioresource Technology, vol. 99, no. 6, pp. 1563-1570, 2008.

[44] M. Tuzen, K. O. Saygi, and M. Soylak, "Solid phase extraction of heavy metal ions in environmental samples on multiwalled carbon nanotubes," Journal of Hazardous Materials, vol. 152, no. 2, pp. 632-639, 2008.

[45] M. Tuzen and M. Soylak, "Multiwalled carbon nanotubes for speciation of chromium in environmental samples," Journal of Hazardous Materials, vol. 147, no. 1-2, pp. 219-225, 2007.

[46] R. Q. Long and R. T. Yang, "Carbon nanotubes as superior sorbent for dioxin removal," Journal of the American Chemical Society, vol. 123, no. 9, pp. 2058-2059, 2001.

[47] M. Shirmardi, A. R. Mesdaghinia, A. H. Mahvi, S. Nasseri, and R. Nabizadeh, "Kinetics and equilibrium studies on adsorption of acid red 18 (Azo-Dye) using multiwall carbon nanotubes (MWCNTs) from aqueous solution," E-Journal of Chemistry, vol. 9, no. 4, pp. 2371-2383, 2012.

[48] G. Absalan, M. Asadi, S. Kamran, L. Sheikhian, and D. M. Goltz, "Removal of reactive red-120 and 4-(2-pyridylazo) resorcinol from aqueous samples by $\mathrm{Fe}_{3} \mathrm{O}_{4}$ magnetic nanoparticles using ionic liquid as modifier," Journal of Hazardous Materials, vol. 192, no. 2, pp. 476-484, 2011.

[49] K. S. Thangamani, M. Sathishkumar, Y. Sameena et al., "Utilization of modified silk cotton hull waste as an adsorbent for the removal of textile dye (reactive blue MR) from aqueous solution," Bioresource Technology, vol. 98, no. 6, pp. 1265-1269, 2007.

[50] Z. Aksu and S. Tezer, "Biosorption of reactive dyes on the green alga Chlorella vulgaris," Process Biochemistry, vol. 40, no. 3-4, pp. 1347-1361, 2005.

[51] J. Liu, A. G. Rinzler, H. Dai et al., "Fullerene pipes," Science, vol. 280, no. 5367, pp. 1253-1256, 1998.

[52] R. K. Rajoriya, B. Prasad, I. M. Mishra, and K. L. Wasewar, "Adsorption of benzaldehyde on granular activated carbon: kinetics, equilibrium, and thermodynamic," Chemical and Biochemical Engineering Quarterly, vol. 21, no. 3, pp. 219-226, 2007.

[53] T. Madrakiana, A. Afkhami, M. Ahmadi, and H. Bagheri, "Removal of some cationic dyes from aqueous solutions using magnetic-modified multi-walled carbon nanotubes," Journal of Hazardous Materials, vol. 196, pp. 109-114, 2011.
[54] S. Cengiz and L. Cavas, "Removal of methylene blue by invasive marine seaweed: Caulerpa racemosa var. cylindracea," Bioresource Technology, vol. 99, no. 7, pp. 2357-2363, 2008.

[55] M. Anbia and S. A. Hariri, "Removal of methylene blue from aqueous solution using nanoporous SBA-3," Desalination, vol. 261, no. 1-2, pp. 61-66, 2010.

[56] C. Crittenden, R. Turssel, D. Hand, K. Howe, and G. Tchobanoglous, Water Treatment: Principles and Design, John Wiley \& Sons, New York, NY, USA, 2005. 

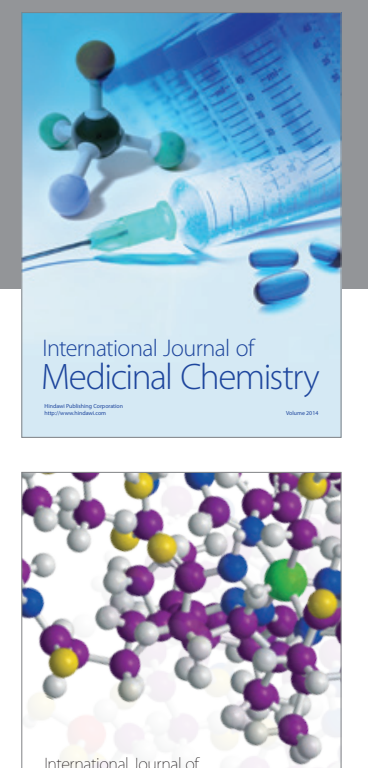

\section{Carbohydrate} Chemistry

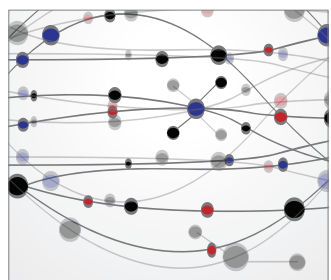

The Scientific World Journal
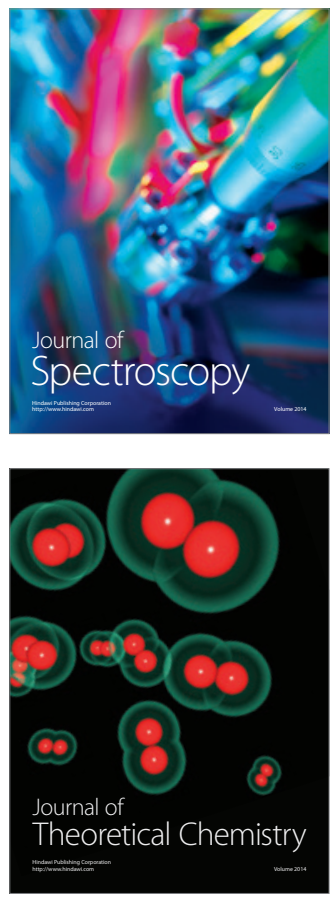
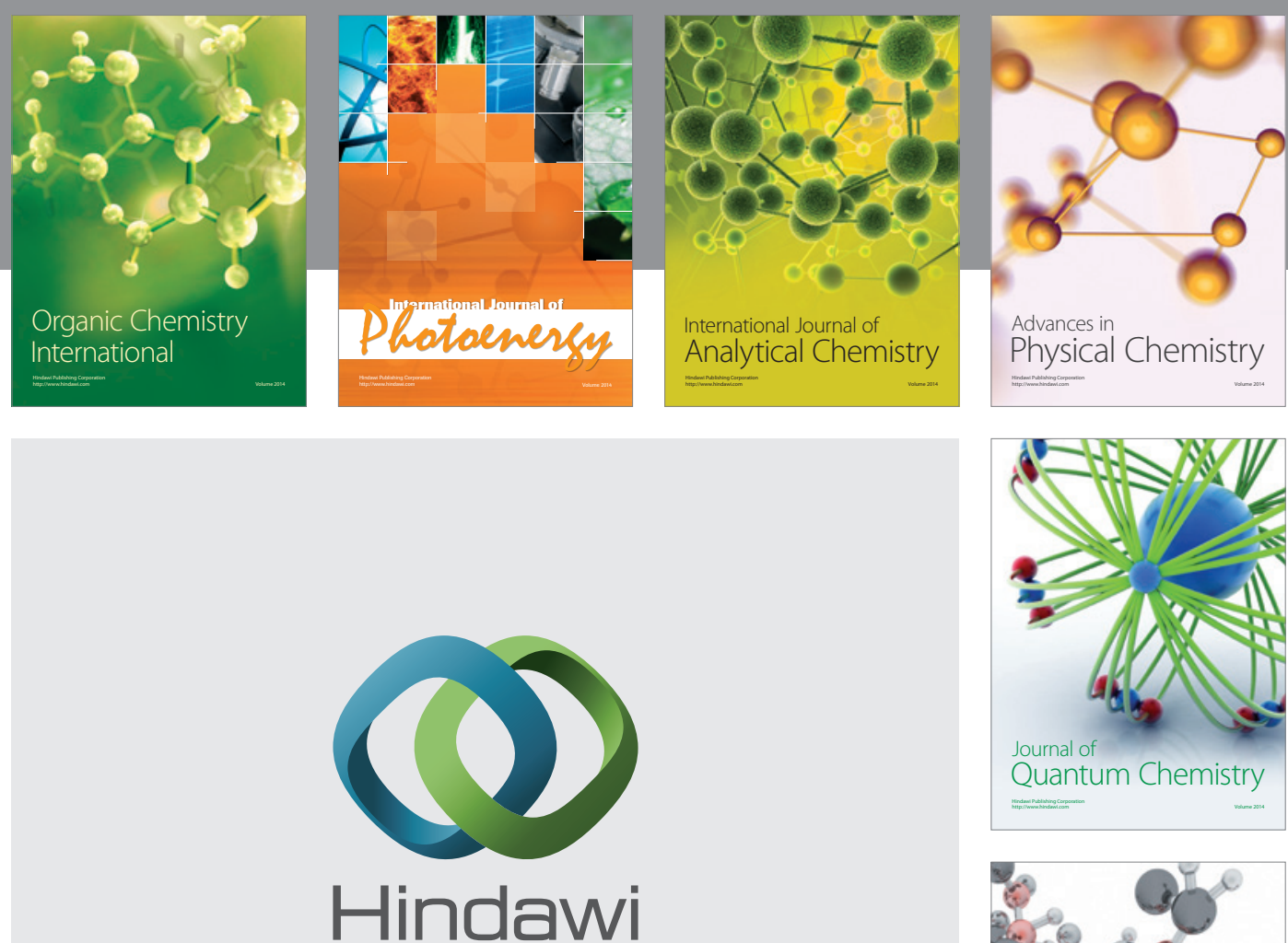

Submit your manuscripts at

http://www.hindawi.com

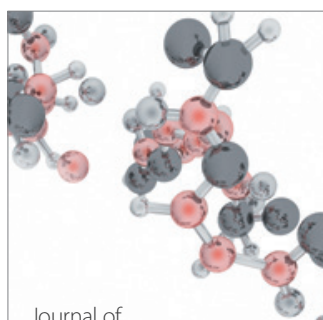

Analytical Methods

in Chemistry

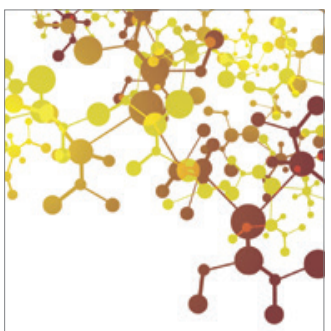

Journal of

Applied Chemistry

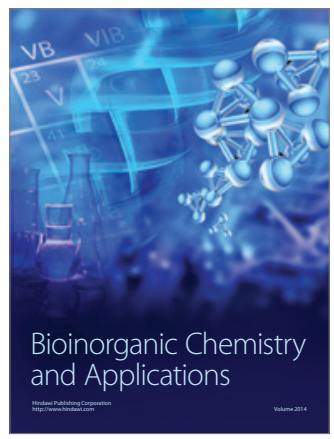

Inorganic Chemistry
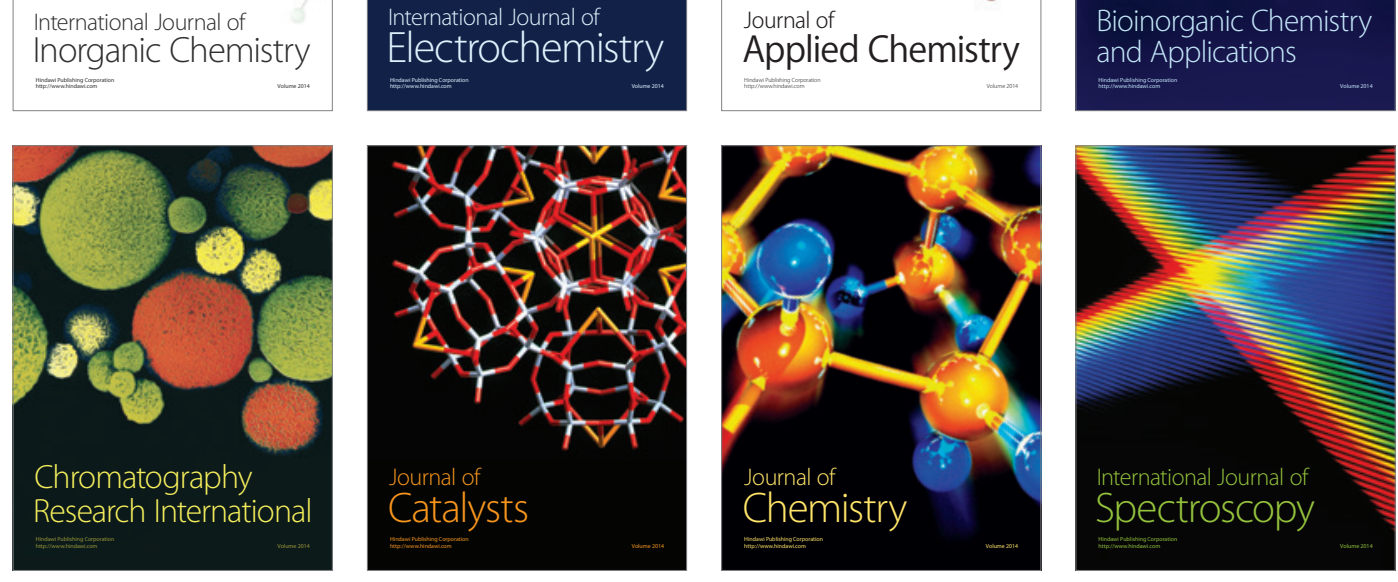